\title{
ANÁLISE AMBIENTAL, SANITÁRIA E ECONÔMICA DE UM SISTEMA DE TRATAMENTO DE RESÍDUOS SÓLIDOS E EFLUENTES EM UMA GRANJA DE SUÍNOS
}

\author{
Evelyne Cazarotto Farezin ${ }^{1}$ \\ Juliana Sarubbi ${ }^{2}$ \\ Jean Louis Rabello de Morais ${ }^{3}$ \\ Waldemar Hazoff Junior ${ }^{2}$ \\ Francisco Rafael Martins Soto ${ }^{2}$
}

\begin{abstract}
RESUMO
Os dejetos suínos apresentam potencial poluidor do ponto de vista ambiental e sanitário devido à alta carga de matéria orgânica. Entretanto, quando devidamente tratados, podem apresentar potencial para a geração de produtos de valor agregado. Objetivou-se realizar uma análise ambiental, sanitária e econômica de um sistema de tratamento de resíduos sólidos e efluentes (STRSE) em uma granja tecnificada de suínos de ciclo completo. O STRSE foi constituído basicamente por compostagem, biodigestão anaeróbica e retenção e desidratação do lodo. Foram realizados testes laboratoriais, onde foram avaliados parâmetros físicoquímicos e microbiológicos. A análise de viabilidade econômica do STRSE foi amparada na técnica de orçamento de capital. O STRSE foi capaz de tratar os resíduos orgânicos e os efluentes tornando-os incapazes de causarem danos ambientais e sanitários. Houve também ganho social e redução de passivos ambientais. Na análise econômica, o STRSE levará cerca de nove anos para amortizar o capital investido.
\end{abstract}

Palavras-chave: compostagem, biodigestão anaeróbica, biogas, biofertilizante, coliformes.

\section{ENVIRONMENTAL, SANITARY AND ECONOMIC ANALYSIS OF A SYSTEM OF TREATMENT OF SOLID WASTE AND EFFLUENTS IN A SWINE FARM}

\begin{abstract}
The swine manure have pollution potential of environmental and sanitary point of view due to the high organic matter content. However, when properly treated, may present potential for generating value-added products. This study aimed to carry out an environmental analysis, health and economic of a solid waste treatment system and wastewater (WTSW) in a technified swine farm full cycle. The WTSW was formed basically by composting, anaerobic digestion and retention and sludge dehydration. Laboratory tests were evaluated in chemical and microbiological physical parameters were performed. The economic viability of WTSW analysis was supported in capital budgeting technique. The WTSW was able to treat organic waste effluents and rendering them unable to cause environmental and health damage. There was also gain social and reduction of environmental liabilities. In the economic analysis, WTSW will take about nine years to amortize the capital invested.
\end{abstract}

Keywords: composting, anaerobic biodigestion, biogas, biofertilizers, coliforms.

\footnotetext{
${ }^{1}$ Acadêmica de Zootecnia - Universidade Federal de Santa Maria (UFSM) Campus Palmeira das Missões-RS.

${ }^{2}$ Professora Adjunta do Departamento de Zootecnia e Ciência Biológicas - Universidade Federal de Santa Maria (UFSM) Campus Palmeira das Missões-RS.

${ }^{3}$ Técnologo em Gestão Ambiental.
}

Farezin EC, Sarubbi J, Morais JLR, Hozoff Junior W, Soto FRM. Análise ambiental, sanitária e econômica de um sistema de tratamento de resíduos sólidos e efluentes em uma granja de suínos. Vet. e Zootec. 2018 mar.; 25(1): 164-172. 


\section{ANÁLISIS AMBIENTAL, SANITÁRIA Y ECONÓMICA DE UN SISTEMA DE TRATAMIENTO DE RESIDUOS SÓLIDOS Y EFLUENTES EN UNA GRANJA DE CERDOS}

\section{RESUMEN}

El estiércol de cerdo tiene un potencial de contaminación desde un punto de vista del medio ambiente y la sanidad, debido al alto contenido de materia orgánica. Sin embargo, cuando se trata adecuadamente, puede presentar potencial para generar productos de valor añadido. Este estudio tuvo como objetivo llevar a cabo un análisis del medio ambiente, la sanidad y económica de un sistema de tratamiento de residuos sólidos y aguas residuales (STRSAR) en una granja tecnificada ciclo completo de cerdos. El STRSAR fue formada básicamente por compostaje, digestión anaerobia y la retención y deshidratación de lodos. las pruebas de laboratorio fueron evaluados en parámetros físicos químicos y microbiológicos se llevaron a cabo. La viabilidad económica de análisis STRSAR fue apoyado en la técnica de presupuesto de capital. El STRSAR era capaz de tratar los efluentes de residuos orgánicos y haciéndolos incapaces de causar daños al medio ambiente y la sanidad. También hubo reducción de ganancia social y de los pasivos ambientales. En el análisis económico, STRSAR tomará unos nueve años para amortizar el capital invertido.

Palabras clave: compostaje, biodigestión anaeróbica, biogás, biofertilizante, coliformes.

\section{INTRODUÇÃO}

A carne suína está ganhando cada vez mais espaço no mercado mundial e nacional, onde o consumo desta proteína está em expansão (1). Para atender a demanda que é crescente, a atividade suinícola vem aumentando sua produção nos últimos anos (2) e a expectativa é de crescimento acentuado nos anos vindouros (3). O Brasil encontra-se entre os dez maiores produtores mundiais da carne, estando na quarta posição no ranking de produtores e também nesta colocação no quesito exportação (4). A busca pela maior produção e a criação intensiva contribuem para o aumento da produção de efluentes e de resíduos, que se manejados de forma errônea podem causar diversos desequilíbrios ambientais, sanitários, econômicos e sociais $(1,5,6,7)$.

Os dejetos suínos apresentam potencial poluidor devido à alta carga de matéria orgânica e a eventual presença de patógenos $(8,9)$. Quando estes dejetos e/ou efluentes são lançados no meio ambiente sem tratamento adequado, podem atingir o lençol freático e causar poluição dos recursos hídricos, do ar e a destruição da camada de ozônio, esta última ocasionada pela emissão majoritária de gás metano e óxido nitroso (6).

Os resíduos de serviço de saúde animal (RSSA) também podem gerar sérios impactos ambientais quando descartados inadequadamente (10). Estes RSSA possuem capacidade de infectar e contaminar o meio ambiente e à saúde humana (11). Isso ocorre devido à presença de agentes infecciosos, substâncias químicas, tóxicas, radioativas e objetos perfurocortantes contaminados (12). Além disso, os RSSA podem apresentar diversos micro-organismos que podem sobreviver por tempo considerável nos materiais, tornando-se agentes de disseminação de patógenos para os seres humanos e animais $(13,14)$.

Em relação aos danos sanitários, quando ocorre a decomposição não controlada dos dejetos ou a destinação inadequada dos RSSA, como placentas e animais mortos, há geração de odores e a proliferação de insetos que podem ser reservatórios e/ou vetores de doenças, representando assim um dos principais problemas sanitários (15). 
Os dejetos sólidos e os RSSA orgânicos podem ser tratados por meio da compostagem. Este processo é um dos mais utilizados, pois vem obtendo resultados satisfatórios $(16,17)$. Além disso, gera um composto que pode ser utilizado como adubo apresentando assim valor econômico agregado (18). Já para os demais RSSA, o destino final mais comum em 2013 foi à incineração (44\%), autoclave $(20,5 \%)$, micro-ondas $(2,4 \%)$ e outros $(33,1 \%)(19)$.

Para o tratamento dos dejetos líquidos um importante método é a biodigestão anaeróbica (20). Neste procedimento micro-organismos anaeróbicos degradam a matéria orgânica transformando-a, principalmente, em biogás e em um efluente na qual ainda existe cerca de $1 \%$ de sólidos totais, que deve ser tratado para a produção de biofertilizante e reciclagem de fósforo $(21,22)$. O biogás pode ser empregado na geração de energia elétrica ou térmica e o biofertilizante como adubo orgânico, sendo principalmente fonte de fósforo na agricultura (23). Desta forma, tem-se a geração de produtos de valor agregado, que possibilitam uma maior geração de renda na atividade suinícola e a produção sustentável, contemplando assim o aspecto ambiental, sanitário, econômico e social (24).

Diante deste cenário, objetivou-se realizar uma análise ambiental, sanitária e econômica de um sistema de tratamento de resíduos sólidos e efluentes (STRSE) em uma granja de suínos.

\section{MATERIAL E MÉTODOS}

O trabalho foi realizado em uma granja de suínos tecnificada de ciclo completo com 300 matrizes alojadas, localizada no município de Ibiúna (SP). O período de avaliação foi compreendido entre 02 de Janeiro a 30 de Dezembro de 2015.

Em relação ao STRSE, especificamente na geração de resíduos sólidos orgânicos (RSO) e efluentes na granja, no setor de maternidade e gestação, todos os dias ocorria à limpeza a seco, gerando desta forma RSO (dejetos e cama de serragem) passiveis de serem tratados por vermicompostagem. Os efluentes (dejetos líquidos, urina e água de consumo e de limpeza) eram produzidos em menor quantidade nestas instalações, pois a higienização com água era menos frequente. Já nos setores de creche e crescimento e terminação a limpeza era efetuada com água sob pressão todos os dias (figura 1, etapa 1). A granja apresentava telhado térmico que cobria a canaleta condutora (figura 1, etapa 2) para evitar a mistura de água pluvial com o efluente.

Os RSSA orgânicos (placentas, natimortos e animais mortos) eram tratados pelo processo de vermicompostagem. Estes RSSA juntamente com os RSO eram coletados pelos funcionários da granja todos os dias e transportados até a usina de biofertilizante (figura 1, etapa 4), onde eram armazenados em caixas de alvenaria (figura 1, etapa 4b) e piso de concreto para evitar a contaminação do lençol freático. O RSSA orgânico era misturado com o RSO em uma relação de 6:1 (25). Após 70 dias, tempo necessário para estabilização térmica do material ocorria à colocação de minhocas da espécie Eudrilus eugeniae e após 60 dias, todo o RSO e o RSSA orgânico estavam transformados em húmus, pronto para comercialização (26).

Os RSSA inorgânicos (seringas, agulhas, frascos de vacinas, antibióticos, ampolas de inseminação, entre outros) eram gerados em maior quantidade na maternidade e na gestação, principalmente nos dias que ocorriam os partos e as inseminações (segunda, terça e quartafeira). Eles eram segregados semanalmente e os que apresentavam necessidade de tratamento eram submetidos a tríplice lavagem e posterior fervura, o que os tornava passiveis de serem reciclados de forma comum. Após isso, o material apto para reciclagem era conduzido para $o$ armazenamento (figura 1, etapa 1a), para posterior encaminhamento para a cooperativa de reciclagem do município de Ibiúna-SP. $\mathrm{O}$ efluente originário deste procedimento era tratado pelo sistema de biodigestão anaeróbica.

Farezin EC, Sarubbi J, Morais JLR, Hozoff Junior W, Soto FRM. Análise ambiental, sanitária e econômica de um sistema de tratamento de resíduos sólidos e efluentes em uma granja de suínos. Vet. e Zootec. 2018 mar.; 25(1): 164-172. 


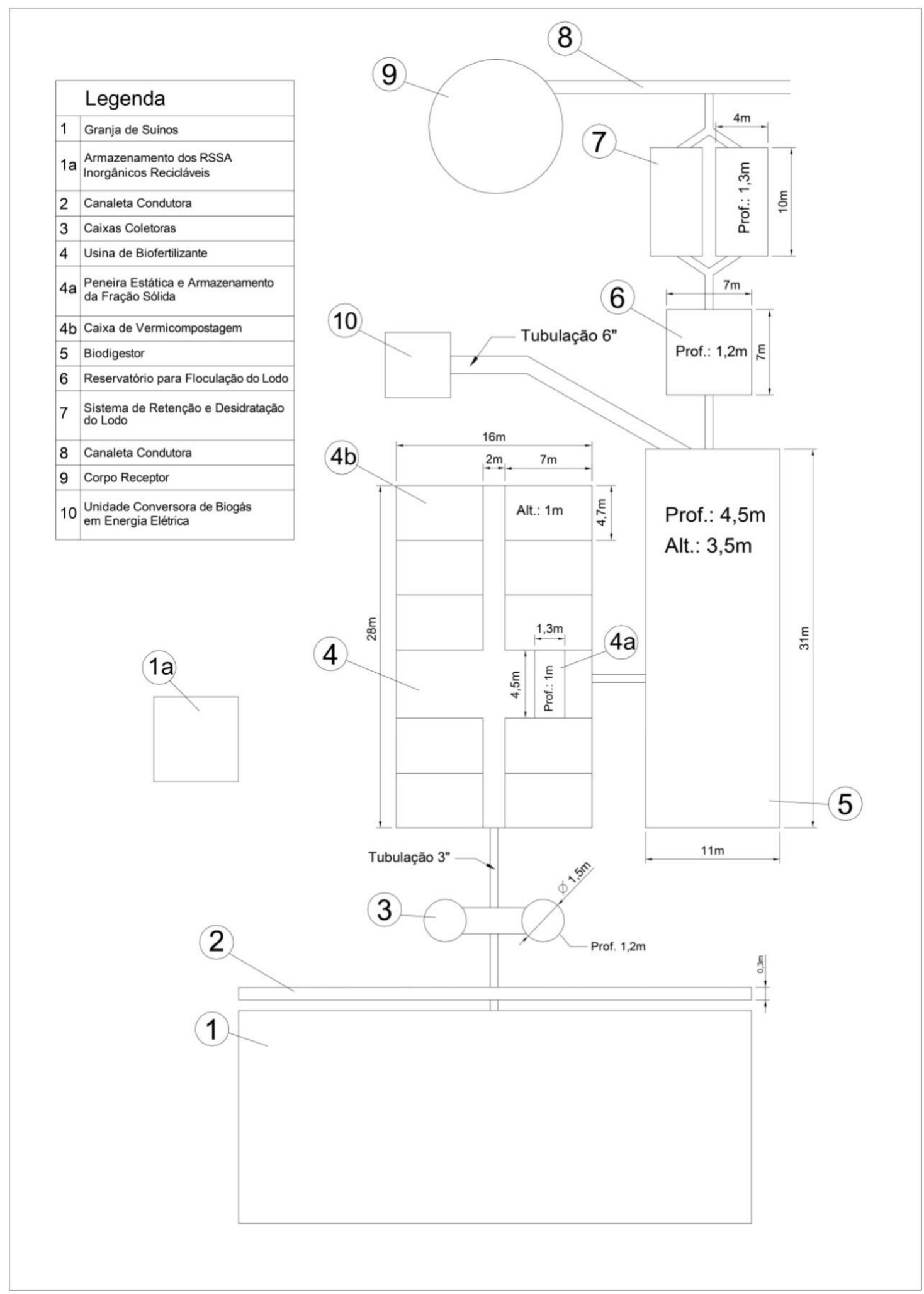

Figura 1. Representação esquemática do sistema de tratamento de resíduos sólidos e efluentes em uma granja de suínos

Os efluentes produzidos nos setores de creche, crescimento e terminação e esporadicamente da maternidade, eram tratados inicialmente pela separação da fração sólida e liquida e posteriormente por biodigestão anaeróbica. Estes eram transportados por uma Farezin EC, Sarubbi J, Morais JLR, Hozoff Junior W, Soto FRM. Análise ambiental, sanitária e econômica de um sistema de tratamento de resíduos sólidos e efluentes em uma granja de suínos. Vet. e Zootec. 2018 mar.; 25(1): 164-172. 
canaleta condutora (figura 1, etapa 2) até as caixas coletoras (figura 1, etapa 3). Na etapa 3, os efluentes eram transportados por meio de uma bomba hidráulica autoescorvante até a usina de biofertilizante (figura 1, etapa 4). Na usina, ocorria a separação da fração sólida e líquida do efluente, em uma peneira estática e de armazenamento da fração sólida (figura 1, etapa 4a). A fração líquida era encaminhada para o biodigestor (figura 1, etapa 5), para a produção diária e armazenamento de $700 \mathrm{~m}^{3}$ de biogás. A fração sólida era encaminhada para caixas de alvenaria e submetida também ao tratamento por vermicompostagem para a produção de húmus de minhoca (figura 1, etapa 4b). O biogás era conduzido para a unidade conversora de biogás em energia elétrica (figura 1, etapa 10) e abastecia a propriedade por cerca de 10 a 12 horas/dia. O efluente originário do biodigestor era encaminhado para um reservatório com o uso de misturadores elétricos e utilização de polímeros para a floculação do lodo (figura 1, etapa 6) e após esta fase, para o sistema de retenção e desidratação do lodo constituído por bags de material geotêxtil (figura 1, etapa 7) e posterior produção de biofertilizante (figura 1, etapa $4 b$ ). Na fase 7, o efluente era transformado em água de reuso que era lançada em uma canaleta (figura 1, etapa 8) e posteriormente no corpo receptor (figura 1, etapa 9), onde a mesma era reutilizada para a higienização das instalações da granja.

A usina de biofertilizante era totalmente coberta com telha de fibrocimento e apresentava proteção em todo seu entorno com paredes de alvenaria e tela metálica para evitar a entrada de animais sinantrópicos e outros possíveis vetores de doenças. Este tipo de construção evitava o risco de produção de lixiviado e amplas variações de umidade do resíduo que estava sendo tratado por vermicompostagem. Ademais tal estrutura permitia conforto laboral para os funcionários.

Para a análise ambiental foram realizados testes laboratoriais, onde se avaliou parâmetros como: $\mathrm{pH}$, sólidos totais, nitrogênio, fósforo e demanda química e biológica de oxigênio. Para a análise sanitária investigou-se a presença de coliformes termotolerantes.

A análise de viabilidade econômica do STRSE foi amparada na técnica de orçamento de capital (Payback) que quantificou o tempo em que o produtor levará para recuperar o capital investido (27). Para esta análise foi determinado o montante de capital investido no STRSE e quanto de produtos de valor agregado foram gerados no ano de 2015. Estes produtos foram: biogás convertido em energia elétrica $(\mathrm{kWh})$, húmus de minhoca (tonelada) e biofertilizante (tonelada).

Para efetuar os cálculos de conversão em reais $(\mathrm{R} \$)$ do biogás transformado em energia elétrica, foi utilizado o valor médio cobrado por $\mathrm{kWh} / \mathrm{dia}$ da concessionária do Municipio de Ibiúna- SP, referente ao ano de 2015, que foi de R \$ 0,25 (28). Entretanto, antes foi necessário efetuar o cálculo da quantidade de biogás que cada matriz em média, gerava por dia, posteriormente foi realizado um balanço energético, por $\mathrm{m} 3$, em seguida o balanço foi atualizado para tarifa de energia atual da concessionária.

O húmus de minhoca e o biofertilizante foram calculados a partir do preço médio de venda do mercado regional em 2015, que foi de $\mathrm{R} \$ 300,00$ a tonelada para ambos.

\section{RESULTADOS E DISCUSSÃO}

Em relação a análise ambiental do STRSE, os parâmetros avaliados: pH, sólidos totais, nitrogênio, fósforo e demanda química e biológica de oxigênio foram fortemente influenciados pelo STRSE, principalmente no aspecto da sua redução, o que tornou o efluente ao ser lançado no corpo receptor, incapaz de causar qualquer tipo de dano ambiental e atendeu a legislação vigente (29). O STRSE foi eficiente para sequestrar majoritariamente o gás metano, considerado cerca de 21 vezes mais poluidor que o gás carbônico (30), impedindo assim seu lançamento para a atmosfera, proporcionando a redução de lançamento de gases de efeito estufa. A transformação do RSO e RSSA (orgânico) em húmus de minhoca e do lodo

Farezin EC, Sarubbi J, Morais JLR, Hozoff Junior W, Soto FRM. Análise ambiental, sanitária e econômica de um sistema de tratamento de resíduos sólidos e efluentes em uma granja de suínos. Vet. e Zootec. 2018 mar.; 25(1): 164-172. 
em biofertilizante permitiu a produção de dois produtos com uma relação carbono nitrogênio de aproximadamente 18:1, matéria orgânica estabilizada e mineralizada e com uma elevada porcentagem de micro-organismos altamente benéficos para o solo. Tais atributos proporcionaram elevada capacidade fertilizante e de utilização pelas plantas para o seu crescimento (31) com alto valor ambiental e agronômico.

A segregação e o tratamento dos RSSA inorgânicos no STRSE tornando-os passiveis de serem reciclados de forma comum, apesar de não ter gerado diretamente renda ao produtor, com a sua comercialização, permitiu ganhos sociais e ambientais, com o encaminhamento deste resíduo para a cooperativa de catadores do município e eliminação do seu destino para aterro sanitário e ou incineração, reduzindo a geração de passivos ambientais (32).

Em relação à análise sanitária do STRSE, tanto o efluente que foi lançado no corpo receptor, como o húmus de minhoca e o biofertilizante apresentaram reduções superiores a 98\% de coliformes termotolerantes. Duda e Oliveira (33) em uma pesquisa com reatores em batelada abastecidos com efluente suíno obtiveram valores de redução de 98,88\% de coliformes termotolerantes, resultados praticamente iguais com os encontrados na presente investigação. Esta elevada capacidade de reduzir coliformes termotolerantes no STRSE assume importância ambiental e sanitária, e elege tal método como protagonista no seu tratamento satisfatório com a capacidade de mitigar impactos na saúde pública (34).

A partir da análise econômica foi possível constatar que o STRSE levará cerca de nove anos para recuperar o capital investido, o que corrobora com Westrup et al. (35) que constataram que seriam necessários 8,81 anos para recuperar o capital investido em um sistema semelhante com a geração de energia elétrica a partir do biogás proveniente dos dejetos suínos.

Embora seja um tempo significante, o STRSE além de atingir os objetivos sanitários e ambientais, gerará continuamente produtos de valor agregado, permitindo assim a geração de renda adicional ao produtor a partir do décimo ano $(16,24)$. Existem outros sistemas de tratamento com custos de implantação mais baixos, como é o caso das lagoas de estabilização, mas estas geram contaminação principalmente do ar, devido à produção e emissão de gases que contribuem para o efeito estufa e não geram produtos de valor agregado $(36,37,38)$.

Outro produto gerado pelo STRSE foi a água de reuso, que para o cálculo de orçamento de capital (Payback) não foi quantificada em valor monetário. Entretanto, há relevância ambiental e econômica para a água de reuso, haja visto, os constantes períodos de seca e de racionamento hídrico na qual o Brasil tem passado nos últimos anos tanto na zona urbana como rural do país. A partir do tratamento do efluente após a biodigestão anaeróbica no STRSE, ainda há a possibilidade de geração de outros produtos de valor agregado, como o fósforo orgânico (39). A longo prazo, a possibilidade de geração de créditos de carbono, pode ser também viável no STRSE. Outra vantagem econômica que o STRSE proporcionou foi a melhora da imagem do empreendimento perante aos compradores, fornecedores e entidades públicas, visto que ainda a maioria dos STRSE em granjas de suínos, muitas vezes não contempla nem a etapa da biodigestão anaeróbia, o que torna o suinocultor que não investiu em sistemas de gestão ambiental, ainda mais vulnerável a oscilação de mercado da atividade suinícola. Granjas de suínos com STRSE que produzem biogás e transformam em energia elétrica para consumo próprio acabam ficando menos sensíveis as variações dos preços da energia elétrica e as possíveis faltas desta, o que invariavelmente acaba sendo mais uma vantagem econômica do STRSE avaliado.

Ressalte-se que o tempo de retorno do capital poderá variar entre granjas de tamanhos diferentes, devido ao valor investido por matriz instalada, à capacidade do STRSE e a quantidade de produtos de valor agregado produzidos.

Farezin EC, Sarubbi J, Morais JLR, Hozoff Junior W, Soto FRM. Análise ambiental, sanitária e econômica de um sistema de tratamento de resíduos sólidos e efluentes em uma granja de suínos. Vet. e Zootec. 2018 mar.; 25(1): 164-172. 


\section{CONCLUSÃO}

Com base nos resultados obtidos, pode se concluir que o STRSE foi capaz de tratar os resíduos orgânicos e os efluentes tornando-os incapazes de causarem danos ambientais e sanitários. Em relação aos RSSA inorgânicos o STRSE, permitiu ganhos sociais e redução de passivos ambientais. No aspecto econômico, o STRSE levará cerca de nove anos para recuperar o capital investido.

\section{REFERÊNCIAS}

1. Carvalho BV, Souza APM, Soto FRM. Avaliação de sistemas de gestão ambiental em granjas de suínos. Rev Ambiente Agua. 2015;10(1):164-71.

2. Bonamigo A, Melz MJ, Sehnem S, Wink CA. Manejo dos dejetos de suínos através do sistema de compostagem. Rev Agronegocio Meio Ambiente. 2014;7(3):659-81.

3. Ministério da Agricultura, Pecuária e Abastecimento (BR). Suínos. Brasília: MAPA; 2016.

4. Associação Brasileira de Proteína Animal. Relatório Anual 2015. São Paulo: ABPA; 2015.

5. Williams CMM. Technologies to mitigate environmental impact of swine production. Rev Bras Zootec. 2008;37:253-9.

6. Barbosa G, Langer M. Uso de biodigestores em propriedades rurais: uma alternativa à sustentabilidade ambiental. Unoesc Ciencia ACSA. 2011;2(1):87-96.

7. Meng J, Wang L, Liu X, Wu J, Brookes PC, Xu J. Physicochemical properties of biochar produced from aerobically composted swine manure and its potential use as an environmental amendment. Bioresour Technol. 2013;142:641-6.

8. Palhares JCP, Miranda CR. Gestão ambiental na suinocultura: gestão ambiental da propriedade suinícola. Brasília: Embrapa suínos e aves; 2007.

9. Sá MF, Aita C, Doneda A, Pujol SB, Cantú RR, Jacques IVC, et al. Dinâmica da população de coliformes durante a compostagem automatizada de dejetos líquidos de suínos. Arq Bras Med Vet Zootec. 2014;66(4):1197-206.

10. Giusti L. A review of waste management practices and their impact on human health. Waste Manag. 2009;29(8):2227-39.

11. Silva CE, Hoppe AE. Diagnóstico dos resíduos de serviços de saúde no interior do Rio Grande do Sul. Eng Sanit Ambient. 2005;10(2):146-51.

12. Stefanini M, Moi PCP, Costa PX, Elias RM, Galvão ND, Silva AMC, et al. Responsabilidade sócio-ambiental do cirurgião dentista no gerenciamento dos resíduos de serviços de saúde. Rev Eletronica Connection Line. 2013;10:2-15.

13. Silva ACN, Bernardes RS, Moraes LRS, Reis JDP. Critérios adotados para seleção de indicadores de contaminação ambiental relacionados aos resíduos sólidos de serviços de saúde: uma proposta de avaliação. Cad Saude Publica. 2002;18(5):1401-9. 
14. Nascimento TC, Januzzi WA, Leonel M, Silva VL, Diniz CG. Ocorrência de bactérias clinicamente relevantes nos resíduos de serviços de saúde em um aterro sanitário brasileiro e perfil de susceptibilidade a antimicrobianos. Rev Soc Bras Med Trop. 2009;42(4):415-9.

15. Marinho RC, Oliveira RMS. Avaliação da qualidade do aterro sanitário de Palmas (TO), utilizando a ferramenta índice da qualidade de aterros de resíduos - IQA. Rev Nac Gerenc Cidades. 2013;1(2):123-41.

16. Soto FRM, Coelho CP, Benites NR, Bonamin LV, Melville PA. Elimination of E. coli from piglet carcases using an on-farm composting system. Vet Rec. 2010;166(18):564-5.

17. Sunada NS, Orrico ACA, Orrico Júnior MAP, Centurion SR, Oliveira ABM, Fernandes ARM, et al. Compostagem de resíduo sólido de abatedouro avícola. Cienc Rural. 2014;45(1):178-83.

18. Abreu PG, Pedroso-de-Paiva D, Abreu VMN, Coldebella A, Cestonaro T. Casca de arroz e palhada de soja na compostagem de carcaças de frango de corte. Acta Sci Anim Sci. 2011;33(1):51-7.

19. Associação Brasileira de Empresas de Limpeza Pública e Resíduos Especiais. Panorama dos resíduos sólidos no Brasil 2013. Abrelpe; 2013.

20. Machado NS, Silva JN, Oliveira MVM, Costa JM, Borges AC. Remoção do sulfeto de hidrogênio do biogás da fermentação anaeróbia de dejetos de suínos utilizando óxido de ferro, hidróxido de cálcio e carvão vegetal. Rev Energ Agric. 2015;30(4):344-56.

21. Souza CF, Santos CR, Campos JA, Mogami CA, Bressan WS. Potencial de dejetos suínos como substrato na biodigestão anaeróbia sob efeito de diferentes temperaturas e tempos de retenção hidráulica. Rev Ceres. 2005;52(300):255-65.

22. Suárez AG, Nielsen K, Köhler S, Morencio DO, Reyes IP. Enhancement of anaerobic digestion of microcrystalline cellulose (MCC) using natural micronutrient sources. Braz $\mathrm{J}$ Chem Eng. 2014;31(2):393-401.

23. Pereira MS, Godoy TP, Godoy LP, Bueno WP, Wegner RS. Energias renováveis: biogás e energia elétrica provenientes de resíduos de suinocultura e bovinocultura na UFSM. Rev Eletronica Gest Educ Tecnol Ambiental. 2015;19(3):239-47.

24. Manning DT, Hadrich JC. An evaluation of the social and private efficiency of adoption: Anaerobic digesters and greenhouse gas mitigation. J Environ Manag. 2015;154:70-7.

25. Maragno ES, Trombin DF, Viana E. O uso da serragem no processo de minicompostagem. Eng Sanit Ambient. 2007;12(4):355-60.

26. Soto FRM, Bernardi F, Camargo SR. Avaliação econômica e ambiental de sistema de tratamento de dejetos e carcaças em uma granja comercial de suínos. Vet Zootec. 2007;14(2):246-51. 
27. Gitman LJ. Princípios de administração financeira. 10a ed. São Paulo: Pearson Education; 2004.

28. Cooperativa de Eletrificação de Ibiúna. Ibiúna: CETRIL; 2016.

29. Conselho Nacional do Meio Ambiente (BR). Resolução no 430, de 13 de Maio de 2011. Dispõe sobre as condições e padrões de lançamento de efluentes, complementa e altera a Resolução no 357, de 17 de Março de 2005, do Conselho Nacional do Meio AmbienteCONAMA. Diário Oficial da União. 16 Maio 2011.

30. Whitehead DC. Grassland nitrogen. Wallingford: CAB International; 1995.

31. Montoro SB, Santos DFL, Junior JL. Análise econômica de investimentos que visam à produção de biogás e biofertilizante por meio de biodigestão anaeróbia na bovinocultura de corte. RAUnP. 2013;5(2):23-34.

32. Gessner R, Piosiadlo LCM, Fonseca RMGS, Larocca LM. O manejo dos resíduos dos serviços de saúde: um problema a ser enfrentado. Cogitare Enferm. 2013;18(1):117-23.

33. Duda RM, Oliveira RA. Reatores anaeróbios operados em batelada sequencial seguidos de lagoas de polimento para o tratamento de águas residuárias de suinocultura. Parte II: remoção de nutrientes e coliformes. Eng Agric. 2009;29(1):135-47.

34. Orrico Junior MAP, Orrico ACA, Lucas Junior J, Sampaio AAM, Fernandes ARM, Oliveira EA. Biodigestão anaeróbia dos dejetos da bovinocultura de corte: influência do período, do genótipo e da dieta. Rev Bras Zootec. 2012;41(6):1533-8.

35. Westrup G, Duarte GW, Alberton J, Niehues RC, Rocha DA, Vandresen S. Estudo da viabilidade econômica de geração de energia elétrica a partir de biogás proveniente de dejetos de suínos de uma propriedade rural em Forquilhinha/SC. Revista Ciência e Cidadania. 2015;1(1):19-37.

36. Silva PC, Amaral AA. Tratamento de dejetos suínos com biorreator UASB. Rev Verde Agroecologia Desenvolv Sustent. 2013;8(5):141-7.

37. Santos LD, Mayerle SF, Campos LMS. Tecnologias e sistemas de tratamento para os dejetos da suinocultura. Rev Verde Agroecologia Desenvolv Sustent. 2014;9(5):12-8.

38. Cardoso BF, Oyamada GC, Silva CM. Produção, tratamento e uso dos dejetos suínos no Brasil. Desenvolv Quest. 2015;13(32):127-45.

39. Miele M, Silva MLB, Nicoloso RS, Corrêa JC, Higarashi MM, Kunz A, et al. Tratamento dos efluentes de usinas de biogás. Rev Polit Agric. 2015;24(1):31-46.

Recebido em: Aceito em: 